Oil \& Gas Science and Technology - Rev. IFP, Vol. 57 (2002), No. 5, pp. 443-458

Copyright (C) 2002, Éditions Technip

\title{
Subsidence Delay: Field Observations and Analysis
}

\author{
M. Hettema ${ }^{1}$, E. Papamichos ${ }^{2 *}$ and P. Schutjens ${ }^{2 * *}$ \\ 1 STATOIL, Stavanger - Norway \\ 2 SINTEF Petroleum Research, Trondheim - Norway \\ e-mail: mheH@statoil.com - epapamic@civil.auth.gr \\ *Presently at Aristotle University of Thessaloniki - Greece. \\ **On temporary assignment from Shell Research SEPTAR, Rijswijk - The Netherlands.
}

\begin{abstract}
Résumé — Subsidence différée : observations et analyse à partir de données de champs — L'objectif de cet article est de décrire l'effet différé de subsidence liée à la déplétion à partir des observations de terrain, dans le but d'expliquer ses origines et de mieux contraindre sa modélisation. L'évolution non linéaire de la subsidence en surface en fonction de la déplétion du réservoir peut être étudiée à partir du décalage entre le début de la production et le démarrage (différé) de la subsidence. Nous avons analysé des données provenant de huit champs d'hydrocarbures et quantifié l'effet de décalage entre la subsidence et la déplétion et le temps de retard correspondant. Les temps de retard quantifiés varient de 1,6 à 13 ans. Les champs étudiés ont été classifiés selon leur profondeur, âge et type de roche. Afin d'expliquer les observations de terrain, les données ont été confrontées à quatre mécanismes :

- diffusion de la pression interstitielle ;

- effet du recouvrement ;

- comportement du réservoir en compaction ;

- déformation du recouvrement, de la base ou de l'extension du réservoir.

L’importance relative de ces mécanismes a été déterminée à partir de l'analyse des données de terrain. Certains mécanismes peuvent être éliminés à partir de principes théoriques de base alors que d'autres apparaissent comme inappropriés. Il est montré que le mécanisme de diffusion de la pression interstitielle contribue toujours à un effet différé, mais que cet effet est trop faible pour expliquer les observations de champ. Dans le cas de réservoirs contenant de l'argile, la surcompaction naturelle peut expliquer les temps de retard observés. En général, les autres mécanismes de compaction des réservoirs (tels que fluage, effet de la vitesse de chargement sur le comportement de la roche et transition élastoplastique) peuvent également être la cause principale de l'effet de décalage entre la subsidence et la déplétion.
\end{abstract}

\footnotetext{
Abstract - Subsidence Delay: Field Observations and Analysis - The objective of this paper is to describe the subsidence-depletion delay from field observations with the aim to explain its cause and constrain its modelling. The nonlinearity in the surface subsidence response to the reservoir depletion can be seen as a shift between the start of the depletion and the (delayed) start of the subsidence. We have analysed data of eight hydrocarbon fields to quantify the subsidence-depletion delay effect and the corresponding time-delay. The time-delays appeared to be in the range of 1.6 to 13 years. The fields were categorised according to their depth, age and rock type. To explain the field observations, the data was tested against four categories of mechanisms:

- pore pressure diffusion effects;

- overburden inertia;
} 


\section{- reservoir compaction behaviour; \\ - deformation of the over- under-and side-burden.}

The relative importance of these mechanisms was assessed from an analysis of the field data. Some mechanisms could be rejected based on theoretical grounds and others appeared to be irrelevant. It is concluded that pore pressure diffusion always contributes to a delay effect but that its effect is too low to explain the field observations. For the shallow reservoirs, natural over-compaction has the potential to cause the observed subsidence-depletion delay. In general, the other reservoir compaction related mechanisms (such as creep, an intrinsic rate effect and an elastic-plastic transition) could also be the main cause of the subsidence-depletion delay effect.

\section{INTRODUCTION}

Lowering the reservoir pressure during production (depletion) increases the stress carried by the load-bearing framework of the reservoir rock. It triggers grain-scale deformation mechanisms causing elastic (recoverable) and inelastic (permanent) reservoir strain, which is partly timedependent. One of the major consequences of reservoir compaction is surface subsidence, which can have severe technical, safety and environmental impacts (Doornhof, 1992; Freeze, 2000). Accurate modelling of depletioninduced subsidence requires an understanding of the mechanical behaviour of the reservoir and surrounding rock in response to the depletion. Laboratory experiments on core material have provided insight in the rock compressibility under in situ stress and temperature conditions, and this data has been used by many oil and water production companies to model compaction and surface subsidence.

Early models relating compaction to subsidence stem from the pioneering work of Terzaghi (1950), Geertsma (1973) and Geertsma and Van Opstal (1973). The "nucleus of strain" model of Geertsma (1973) assumed linear poroelastic rock behaviour, and both the reservoir and the surrounding rock were considered homogeneous and having the same material properties. This implies that subsidence instantaneously follows the reservoir compaction and that there is a linear relationship between depletion and compaction, and also between depletion and subsidence. Although linear elasticity is a highly idealised material behaviour, linear or near-linear relationships between stress and strain have often been observed in laboratory experiments on core, in particular in cemented sandstone at stress states close to in situ stresses, far away from any yield or failure envelope (Schutjens et al., 2000; Hettema et al., 2000; Schutjens et al., 2001). This is confirmed by in situ compaction measurements for the Groningen reservoir, which also show a linear relationship between compaction and pressure depletion (Mobach and Gussinklo, 1994).

Models based on linear elasticity fail to explain a subtle yet apparently consistent effect of depleting reservoirs: subsidence may show a nonlinear dependence on reservoir pore pressure. After a while, the subsidence versus pressure curve becomes rather linear and quantitatively in better agreement with compaction studies based on laboratory core measurements. Figure 1 shows, in schematic form, that this nonlinearity in the subsidence response to the depletion can be seen as a shift between the start of the depletion and the (delayed) start of the subsidence. This phenomenon will hereafter be referred to as the subsidence-depletion delay effect.

This phenomenon has been observed before (Merle et al., 1976; de Waal and Smits, 1985; Boutéca et al., 1990; McLendon, 1991). Unfortunately, only a few subsidence fields have reliable early measurements available. This could be due to:

- confidentiality of the data;

- lack of early measurements, often because subsidence was not anticipated, or

- subsidence was badly documented or not measured at all.

Our paper is structured as follows. In the next section, the employed methodology is described. This is followed by a short description of each field, the field data and the resulting subsidence-depletion delays and time-delays. Then, some

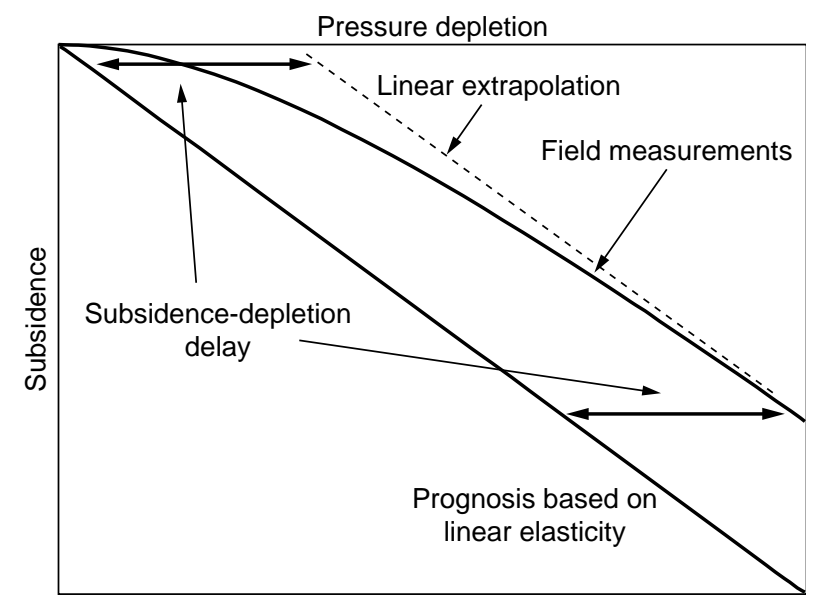

Figure 1

Sketch showing a prognosis based on linear elasticity compared to typical field measurements. The plot also shows how the subsidence-depletion delay is determined from field data by a linear extrapolation. 
mechanisms for the subsidence-depletion delay effect are tested against the field data. The field data is used to limit the number of relevant mechanisms and to quantify their importance. The results are then discussed and finally, the conclusions are drawn.

\section{METHODOLOGY}

We have analysed subsidence data from eight hydrocarbon fields. Table 1 shows an overview of some key data of the fields investigated in this study. The depth is the true vertical depth subsurface. For the offshore fields (Valhall, Ekofisk and Troll), the sub seafloor depths are given. We used both data available in the open literature together with new data on the time history of subsidence, reservoir depletion pressure and/or cumulative production.

Often initially nonlinear behaviour is observed, when analysing the surface subsidence from subsidence versus time plots. This nonlinearity could be the result of several time-dependent processes, including effects of varying production rates and/or nonlinear depletion with time. We regard the reservoir pressure depletion as the mechanical parameter controlling the subsidence. To rule out effects due to variations in reservoir pressure on the subsidence, we determine a subsidence-depletion delay from the subsidence versus the (average) reservoir depletion plot. The subsidencedepletion delay and the time delay are determined in three steps:

- A linear regression line is determined from the nearlinear part of the subsidence-depletion curve.

- The subsidence-depletion delay is defined as the depletion axis cut-off of the linear regression line.
- The time-delay is determined from the time at which the reservoir depletion was equal to the subsidence-depletion delay.

One of the objectives was to investigate a "natural" delay phenomenon, which possibly occurs during the primary recovery of a reservoir. Care was taken to exclude data recorded during a secondary recovery period or after significant production stimulation. For the investigated gas fields this was not a problem, but some oilfields were subjected to water flood, steam soak, steam drive or massive hydraulic fracturing. In those cases only early field data was used, recorded during the natural depletion period of the field.

\section{ANALYSIS OF THE SUBSIDENCE-DEPLETION DELAY}

\subsection{The Lacq Gas Field}

The Lacq gas field in southwest France is a carbonate reservoir. The reservoir is of Upper Jurassic to Lower Cretaceous age and is in production since 1957. We used data from Boutéca et al. (1996) and Rolando et al. (1997) to obtain the subsidence and the reservoir depletion data. The subsidence data presented in Figure 2 indicate that after an initial period, there is a linear relationship between subsidence and depletion. By linear extrapolation of the data to zero subsidence, the subsidence-depletion delay is $2.2 \mathrm{MPa}$ and the corresponding time-delay is 2.2 years. However, the extrapolation is very uncertain because there are only 3 data points available over a 27 -year period. The subsidence-depletion delay is very sensitive to the inaccuracy of the subsidence measurements, especially to that of the first subsidence measurement, taken 10 years after production start.

TABLE 1

Some key data of the investigated fields

\begin{tabular}{|c|c|c|c|c|}
\hline Field, location & Formation type & Hydrocarbon produced & Average depth (m) & $\begin{array}{l}\text { Initial reservoir } \\
\text { pressure (MPa) }\end{array}$ \\
\hline Lacq, France & Carbonate (limestone/dolomite) & Gas & 4400 & 66.1 \\
\hline Groningen, The Netherlands & Sandstone & Gas & 2900 & 34.7 \\
\hline Ameland, The Netherlands & Sandstone & Gas & 3300 & 55.7 \\
\hline $\begin{array}{l}\text { Bachaquero, } \\
\text { Bolivar coast, Venezuela }\end{array}$ & Uncemented sandstone & Heavy oil & $300-1570$ & $\begin{array}{c}13.8 \\
\text { (at } 1067 \mathrm{~m} \text { ) }\end{array}$ \\
\hline $\begin{array}{l}\text { Tia Juana, M-6, } \\
\text { Bolivar coast, Venezuela }\end{array}$ & Uncemented sandstone & Heavy oil & 610 & 6.3 \\
\hline $\begin{array}{l}\text { Valhall, } \\
\text { North Sea, Norway }\end{array}$ & Chalk & Oil & $2450 *$ & 44.9 \\
\hline $\begin{array}{l}\text { Ekofisk, } \\
\text { North sea, Norway }\end{array}$ & Chalk & Oil & $3000 *$ & 49.3 \\
\hline $\begin{array}{l}\text { Troll East, } \\
\text { North Sea, Norway }\end{array}$ & $\begin{array}{l}\text { Poorly cemented } \\
\text { sandstone }\end{array}$ & Gas & $1150^{*}$ & 15.8 \\
\hline
\end{tabular}

(*) Average sub seafloor depth. 


\subsection{The Groningen Gas Field}

The Groningen gas field in The Netherlands is a sandstone reservoir and it is one of the largest gas fields in the world. The reservoir is of Permean age and in production since 1964. We used data from (Doornhof, 1992) together with data kindly provided by The Dutch Oil Company (NAM) to obtain the time history of subsidence and reservoir depletion. The data presented in Figure 3 indicate that after an initial period, there is a near-linear relationship between subsidence and depletion. By linear extrapolation of the data to zero subsidence, the subsidence-depletion delay is $0.72 \mathrm{MPa}$ and the corresponding time-delay is 3.2 years. The compaction data (Mobach and Gussinklo, 1994) indicate also a linear relationship between compaction and depletion. A possible compaction delay effect cannot be assessed as the data began to be recorded after 1974, 10 years after the start of the production when the reservoir was already depleted about $5 \mathrm{MPa}$.

\subsection{The Ameland Gas Field}

The Ameland gas field in The Netherlands is a sandstone reservoir. The reservoir is of Permean age and is in production since 1985 . We used data kindly provided by The Dutch Oil Company (NAM). The subsidence data shown in Figure 4 indicate that after an initial period, there is a nearlinear relationship between subsidence and depletion. By linear extrapolation of the data to zero subsidence, the subsidence-depletion delay is $2.8 \mathrm{MPa}$ and the corresponding time-delay is 1.6 year.

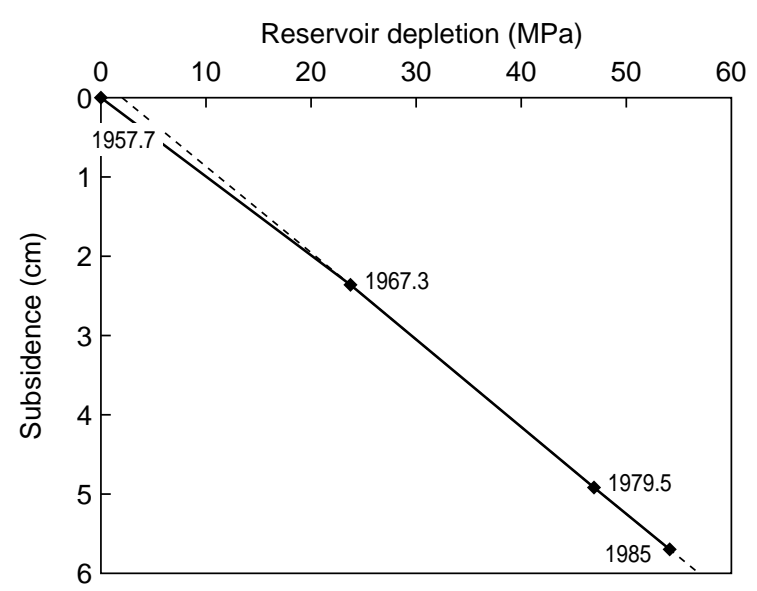

Figure 2

Subsidence versus reservoir depletion data for the Lacq field (data from Boutéca et al., 1996; Rolando et al., 1997).

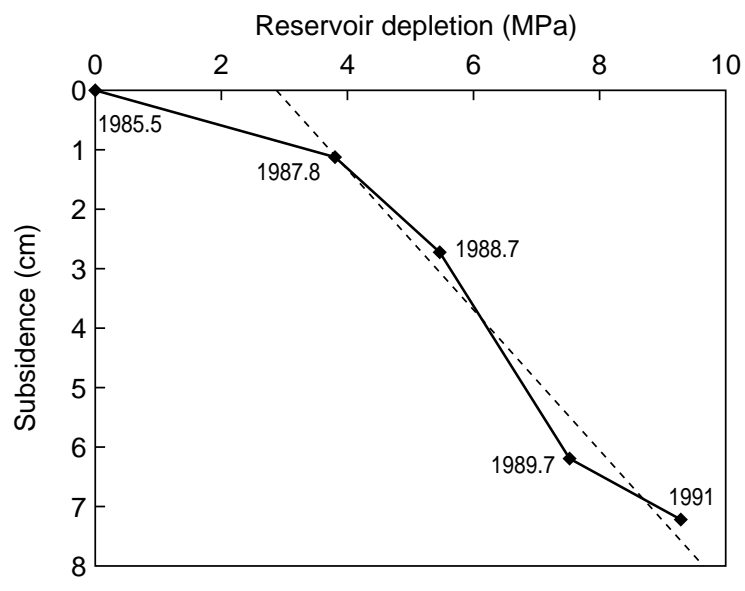

Figure 4

Subsidence versus reservoir depletion data for the Ameland field (data from The Dutch Oil Company, NAM).

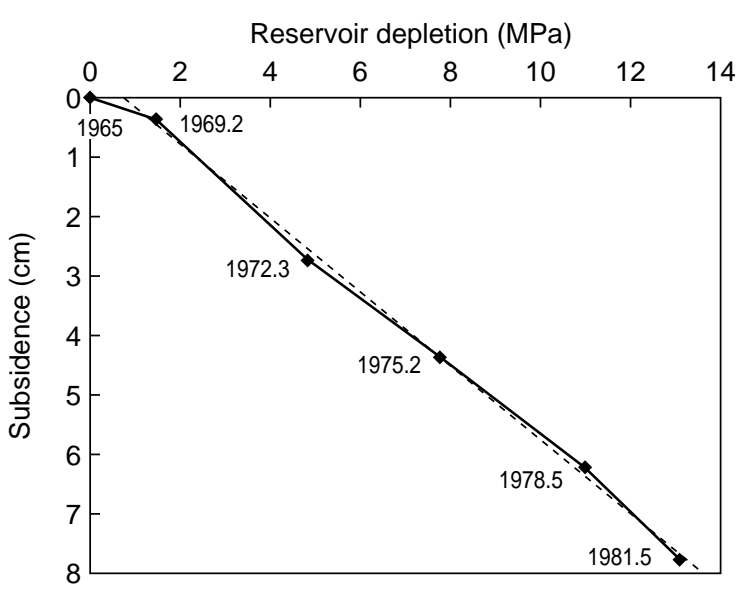

Figure 3

Subsidence versus reservoir depletion data for the Groningen field (data from The Dutch Oil Company, NAM).

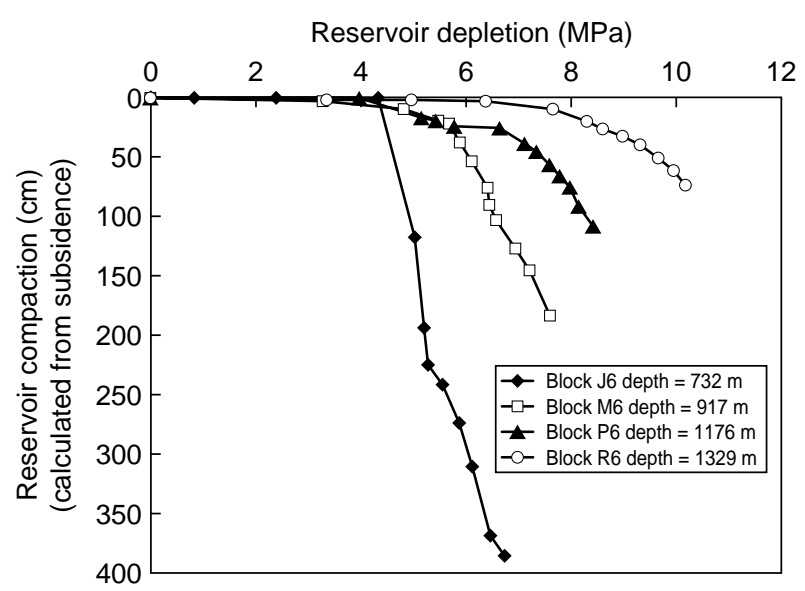

Figure 5

Inferred compaction versus reservoir depletion data for the Bachaquero field (data from Merle et al., 1976). 


\subsection{The Bachaquero Heavy Oil Field}

The Bachaquero heavy oil field lies in the Bolivar coast (East Coast) of Lake Maracaibo in NW Venezuela and is of Oligocene to Miocene age (Tertiary). Field development started in 1936 on land, but production rates increased after World War Two. We used data from Merle et al. (1976) to obtain the reservoir compaction versus the reservoir depletion in four blocks at different depths. The subsurface reservoir compaction was calculated from surface subsidence measurements by using Geertsma's nucleus of strain model (Geertsma, 1973; Van Opstal, 1974). According to Finol and Sancevic (1995) p. 352, quoting earlier work by Núñez and Escojido (1976): “... it is evident that negligible compaction occurs until a certain effective pressure is exceeded, and that the value of this threshold pressure increases with reservoir depth, and that the formation compressibility, as shown by the slopes of the compaction curves in the figure, decreases at greater depths...". Figure 5 shows the calculated reservoir compaction for the blocks at different depths. A strong nonlinear compaction is observed with almost zero compaction up to reservoir depletion in the range 4 to $6 \mathrm{MPa}$. By extrapolating linearly the data to zero compaction, the compaction-subsidence delays are 4.1, 5.4, 6.6 and 7.9 $\mathrm{MPa}$, respectively, for the reservoir blocks at depths 732, 917, 1176 and $1329 \mathrm{~m}$. The subsidence time-delay is estimated to be 12 years (Merle et al., 1976).

\subsection{The Tia Juana Heavy Oil Field}

The Tia Juana heavy oil field lies also in the Bolivar coast (East Coast) of Lake Maracaibo in NW Venezuela and is of Oligocene to Miocene age (Tertiary). We used data from McLendon (1991) and Layrisse (1999) to obtain subsidence versus the reservoir depletion and fluid production of the
M-6 area of Tia Juana. Three production periods are reported for this area:

- primary production 1945-68;

- steam soak (1969-77), and

- steam drive (from 1978).

We have only used data from the primary recovery period until 1968, and this data indicate a subsidence delay (see Fig. 6 ). There are only two subsidence data points available up to 1968, but a linear extrapolation of those points to zero subsidence give a subsidence-depletion delay of 2.0 MPa or $1.5 \mathrm{Mm}^{3}$ of produced fluid. The corresponding time delay is 13 years. This number is uncertain because it was calculated from interpolation between two pressure history data points, assuming a linear depletion rate over time.

\subsection{The Valhall Oil Field}

The Valhall oil field is a chalk field in the Norwegian North Sea. The reservoir is of Upper Cretaceous age and in production since 1982. The reservoir consists of higher porosity chalks in the shallower Tor formation and of lower porosity in the deeper Hod formation. We used data from Cook and Jewell (1996) and Pattillo et al. (1998) to obtain the time history of subsidence, reservoir depletion and fluid production. The reservoir pressure data are averages corrected to a datum of $2500 \mathrm{~m}$ subsea from measured well pressures. The subsidence measurements are for the Valhall platform complex, which lies about $1 \mathrm{~km}$ east from the reservoir crest. Figure 7 shows the subsidence versus reservoir depletion and fluid production. After an initial period, the data indicate a linear relationship between subsidence-depletion and between subsidence-fluid production. By linear extrapolation of the data to zero subsidence, the subsidence-depletion delay is 2.2 $\mathrm{MPa}$ depletion or $3.5 \mathrm{Mm}^{3}$ fluid production. The corresponding time-delay is 2.5 years.

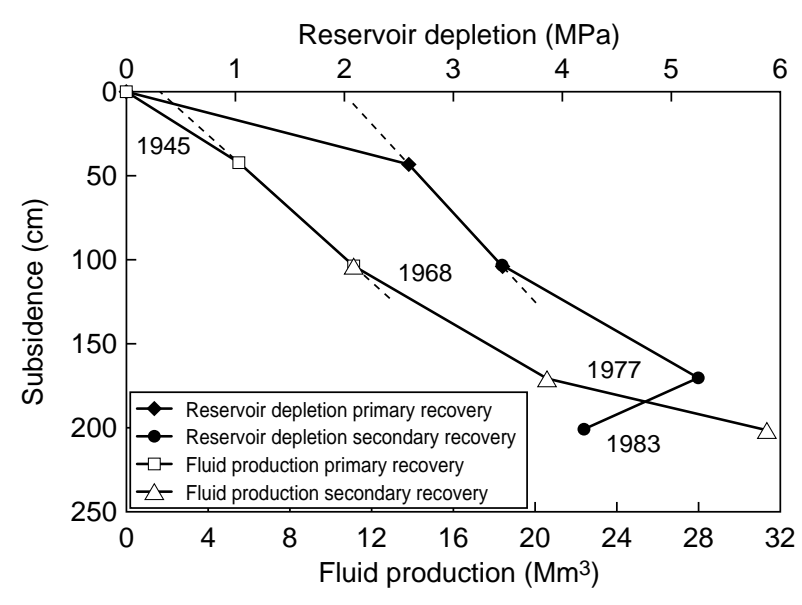

Figure 6

Subsidence versus reservoir depletion and fluid production data for the Tia Juana field (data from McLendon, 1991).

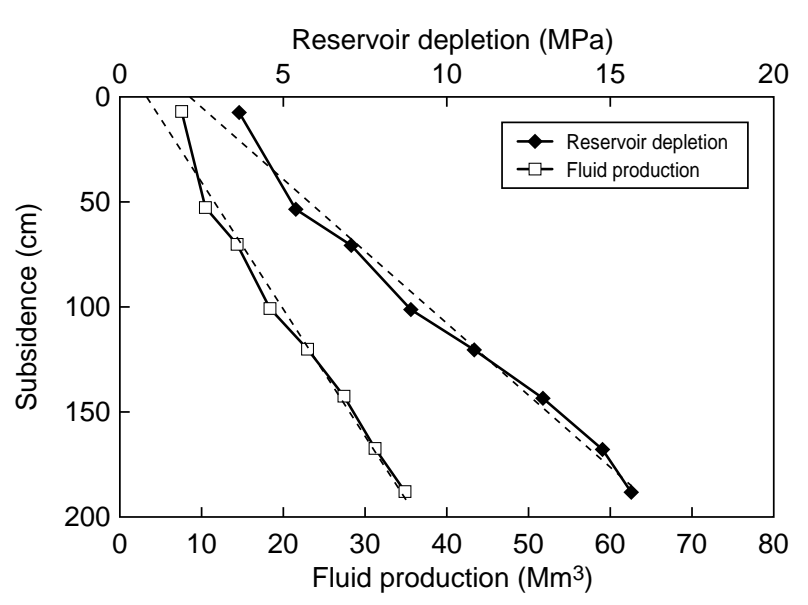

Figure 7

Subsidence versus fluid production data for the Valhall field (data from Cook and Jewell, 1996; Pattillo et al., 1998). 


\subsection{The Ekofisk Oil Field}

The Ekofisk oil field is a large chalk field in the Norwegian North Sea. The reservoir is of Maastrichtian through Upper Danian age (Late Cretaceous to Early Paleocene). The field is in production since 1971, but in 1974 production rates has increased strongly. The reservoir consists of two chalk formations, the Ekofisk formation and the Tor formation. Water injection was initiated in the Tor formation in 1987 and in the entire field in 1994. The time history of subsidence, reservoir compaction and reservoir depletion were obtained from Mathiesen (1996) and Nagel (1998). There were not reported early subsidence measurements, i.e. before 1979, but Mathiesen (1996) reports a 1979 subsidence of $24 \mathrm{~cm}$. Figure 8 presents the subsidence versus reservoir depletion. After an initial period, the subsidence data indicate a near-linear relationship. By extrapolating linearly the data to zero subsidence (data until 1987 when water injection started), the subsidence-depletion delay is $13.0 \mathrm{MPa}$. This subsidence-depletion delay value is strongly dependent on the (modelled) early subsidence. If we take $150 \mathrm{~cm}$ for the 1979 subsidence (data from Jones and Mathiesen, 1993) instead of the $24 \mathrm{~cm}$ used in Figure 8, the subsidencedepletion delay would be $10 \mathrm{MPa}$. The corresponding timedelay is 8 years (from 1971) or 5 years (from 1974).

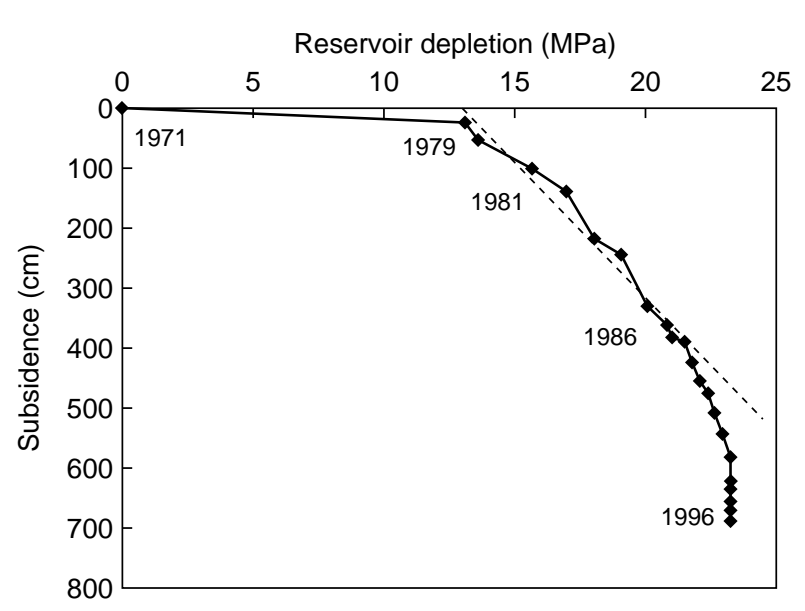

Figure 8

Subsidence versus reservoir depletion data for the Ekofisk field (data from Mathiesen, 1996).

Compaction data began to be recorded at the time when water injection started. A possible compaction delay effect cannot be assessed as the data began to be recorded after 1986, 15 years after the start of the production when the reservoir was already depleted about $20 \mathrm{MPa}$.

\subsection{The Troll East Gas Field}

The Troll East gas field is a large offshore sandstone field in the Norwegian North Sea. The reservoir is of Upper Jurassic age and in production since 1996. At present the reservoir has depleted about 1.4 MPa. The Troll A production platform is monitored by global positioning system (GPS) measurements and measurements of local platform settlement. The results show that up to now (early 2002) the platform has not yet subsided as a result of reservoir production. For Troll, the subsidence-depletion delay appears to be at least 1.4 MPa and the subsidence time delay is at least 6 years.

\section{MECHANISMS FOR THE SUBSIDENCE DELAY EFFECT}

A number of possible mechanisms can cause the observed subsidence-depletion delay effect. In order to structure these causes we divide them into four categories, controlled by two variables:

- the location of the mechanism and

- the process type (active or reactive).

The categories are listed in Table 2.

TABLE 2

Categories for subsidence-delay mechanisms

\begin{tabular}{l|c|c}
\hline $\begin{array}{c}\text { Location } \\
\text { Process }\end{array}$ & Inside the reservoir & Outside the reservoir \\
\hline Driving force & $\begin{array}{c}\text { I } \\
\text { Pore pressure depletion }\end{array}$ & $\begin{array}{c}\text { II } \\
\text { Overburden inertia }\end{array}$ \\
\hline Reaction & $\begin{array}{c}\text { III } \\
\text { Reservoir compaction }\end{array}$ & $\begin{array}{c}\text { IV } \\
\text { Deformation } \\
\text { of over-, under- } \\
\text { and side-burden }\end{array}$ \\
\hline
\end{tabular}

The driving forces are the active processes that cause the subsidence. Due to the pore pressure depletion (I) the effective vertical stress acting on the rock increases due to the fact that a larger part of the overburden weight (II) is carried by the rock. There can be a delay in both the depletion pressure and in the actuation of the overburden weight due to its inertia. At the reaction side, it can be the reservoir compaction (III) that can cause a delay, due to the mechanical behaviour of the reservoir rock. Finally, the reaction of the surrounding rock mass (IV) to the porepressure changes and reservoir compaction can cause a delay. In the following sections these mechanisms are discussed and tested against the field data.

\subsection{Mechanism I: Pore Pressure Depletion}

It is possible that the pore pressure depletion does not occur uniformly throughout the reservoir. Diffusion of pore 
pressure takes time and can therefore cause time delay effects between the local well depletion and the reservoir depletion. Time-delay effects are considered on two length scales:

(A) On a reservoir scale, at the onset of production there is a transient time period during which the drainage boundaries will extend until the outer no-flow boundary is reached. The surface subsidence will be less than expected from the well pressures, because a locally depleted region around the well can easily be supported by the overburden stiffness due to stress arching.

(B) There can be zones of low permeability in the reservoir.

On both scales, time is controlled by pore pressure diffusion. For single-phase flow, the pressure diffusion coefficient is given as (Fjær et al., 1992):

$$
D=\frac{k}{\phi \mu\left(C_{p}+C_{f l}\right)}
$$

Here:

$D$ is the pressure diffusion coefficient $\left(\mathrm{m}^{2} / \mathrm{s}\right)$

$k$ is the permeability $\left(\mathrm{m}^{2}\right)$

$\phi$ is the porosity (-)

$\mu$ is the viscosity (Pa.s)

$C_{p}$ is the pore compressibility (1/Pa)

$C_{f l}$ is the fluid/gas compressibility $(1 / \mathrm{Pa})$.

For cause (A), the transient production time period $t_{p d}$ for a well is given as (Golan and Whitson, 1995):

$$
t_{t p}=0.1 \frac{A}{D}
$$

Here $A$ is the average drainage area per well. For the Venezuelan heavy oil fields, the standard well acreage is used (see Table 3). For the other fields, the area is simply found by dividing the total area of the field by the number of production wells. Since this number of wells often increases during the early development phase, time averages are used.
For the Troll East field, the production wells were drilled from one platform, and the system is regarded as one single drainage point. For the fractured carbonate and chalk reservoirs, the permeability derived from well test data is used rather than the matrix permeability. The properties used in the calculations and the results are shown in Table 3.

Figure 9 shows the calculated transient production time versus the observed subsidence delay time. For all fields, the observed subsidence-delay times are at least a factor 7 larger than the calculated transient production times.

For cause (B), there can be low-permeability zones in the reservoir causing locally time-dependent pressure depletion. For fractured carbonate/chalk reservoirs there are large effective permeability differences between matrix and fractures while for clastic reservoirs, low pore pressure diffusion in low-permeability layers leads to a timedependent increase in vertical effective stress in clays and siltstones (Fjær et al., 1992; Sneed et al., 2000). The production-induced reduction in pore fluid pressure in hydrocarbon reservoirs is many orders of magnitude faster than the gradual changes in pore fluid pressure on the geological time scale (Borchers, 1998). Initially, therefore, production will mainly come from the high-permeability layers, since they provide the optimal pathway for fluid flow towards the wells. As a result, gradients in pore fluid pressure will form between high-permeability (fast depleting) and low-permeability (slowly depleting) zones. Flow of pore fluid will occur along these potential gradients at a rate controlled by the pressure diffusion coefficient. The characteristic time for the depletion of a low-permeability layer (shale layer or unfractured carbonate/chalk matrix body) can be estimated by (Fjær et al., 1992):

$$
t_{c}=\frac{T^{2}}{D}
$$

Here $T$ is the thickness of the shale layer (for clastic reservoirs) or the distance between (assumed parallel) fractures (for chalk/carbonate reservoirs). The diffusion

TABLE 3

Properties (average) and results of the transient production times

\begin{tabular}{l|c|c|c|c|c|c}
\hline Field & $\begin{array}{c}\text { Hydrocarbon } \\
\text { produced }\end{array}$ & $\begin{array}{c}\text { Average permeability } \\
(\mathbf{m D})\end{array}$ & $\begin{array}{c}\text { Viscosity } \\
(\mathbf{m P a} \cdot \mathbf{s})\end{array}$ & $\begin{array}{c}\mathbf{D} \\
\left(\mathbf{m}^{2} / \mathbf{s}\right)\end{array}$ & $\begin{array}{c}\mathbf{A} \\
\left(\mathbf{k m}^{2}\right)\end{array}$ & $\begin{array}{c}\boldsymbol{t}_{\boldsymbol{t}} \\
(\mathbf{y e a r})\end{array}$ \\
\hline Lacq & Gas & 30 & 0.039 & 0.48 & 1.5 & 0.01 \\
Groningen & Gas & 200 & 0.023 & 1.6 & 41 & 0.08 \\
Ameland & Gas & 35 & 0.03 & 0.35 & 23 & 0.21 \\
Bachaquero & Heavy oil & 1300 & 100 & 0.0017 & 0.053 & 0.1 \\
Tia Juana & Heavy oil & 1500 & 2000 & 0.00009 & 0.053 & 1.9 \\
Valhall & Oil & 65 & 0.5 & 0.1 & 8.1 & 0.25 \\
Ekofisk & Oil & 100 & 0.4 & 0.2 & 1.4 & 0.023 \\
Troll East & Gas & 500 & 0.017 & 1.4 & 345 & 0.78 \\
\hline
\end{tabular}




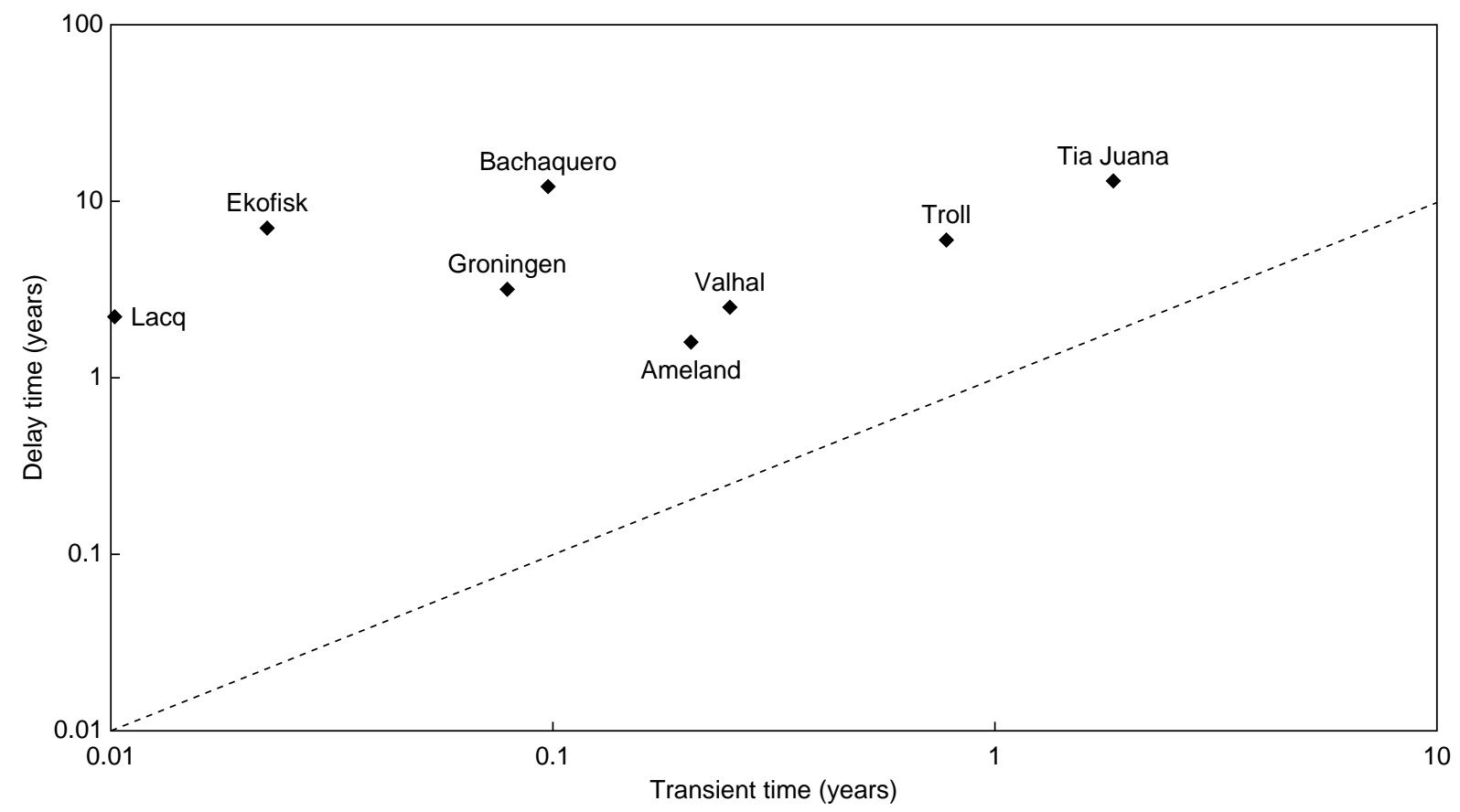

Figure 9

Field-derived delay times versus calculated transient times.

TABLE 4

Characteristic depletion times for low-permeability zones

\begin{tabular}{c|c|c|c|c|c}
\hline \multirow{2}{*}{ Rock type } & Pore fill & $\begin{array}{c}\text { Permeability } \\
(\mathrm{mD})\end{array}$ & $\begin{array}{c}\text { Length scale } \\
1 \mathrm{~m}\end{array}$ & $\begin{array}{c}\text { Length scale } \\
10 \mathrm{~m}\end{array}$ & $\begin{array}{c}\text { Length scale: } \\
50 \mathrm{~m}\end{array}$ \\
\hline Shale & Water & 0.01 & 0.35 days & 0.1 year & 2.4 years \\
Shale & Water & $10^{-6}$ & 9.5 years & 950 years & 24000 years \\
Chalk & Oil & 1 & 0.006 days & 0.6 days & 15 days \\
Carbonate & Gas & 0.001 & 0.7 days & 0.19 year & 4.8 years \\
\hline
\end{tabular}

coefficient $D$ is dominated by the permeability. In clastic reservoirs, the shale and siltstone bodies have a permeability ranging from $10^{-5}$ to $10^{-9} \mathrm{D}$ (Best and Katsube, 1995; Horsrud et al., 1998; Cook, 1999). The Lacq reservoir (carbonate) has an average matrix permeability of $10^{-6} \mathrm{D}$ (Rolando et al., 1997) and the Ekofisk reservoir has a average matrix permeability of $10^{-3} \mathrm{D}$ (Nagel, 1998).

The calculation results in Table 4 suggests that thick shale layers will not deplete significantly on a reservoir production time-scale. On the other hand, blocks of heavily fractured chalk or carbonate (with gas) and relatively high-permeability thin shale beds can be drained within days to months. Thin, low permeability shale bodies or large (un-fractured) carbonate blocks can deplete on the time scale of a few years and thus can contribute to a depletion-delay effect. However, unless these structures make up a significant part of the reservoir volume, this effect cannot explain a subsidencedepletion delay over the entire reservoir.

\subsection{Mechanism II: Overburden Inertia}

It takes time to set in motion a body with a mass by an external force due to its inertia. Because of the large mass of the overburden of a reservoir, there is the potential for a significant time-delay between the application of the force (reservoir depletion) and its actual movement (leading to subsidence). As a result of this inertia, the total vertical stress acting on the reservoir due to the weight of the overburden becomes time-dependent. In the Appendix the inertia effect of the overburden is determined with the use of a simple 
model. It is shown that the inertia effect of the overburden is not relevant for times long compared to (from Eq. A12):

$$
t>\sqrt{\frac{T_{r e s} \sigma_{r e s, 0}}{K_{u} g}}
$$

Here:

$T_{\text {res }}$ is the thickness of the reservoir (m).

$\sigma_{\text {res }}$ is the initial total vertical stress at the top of the reservoir $(\mathrm{Pa})$

$K_{u} \quad$ is the confined modulus $(\mathrm{Pa})$

$g \quad$ is the acceleration of gravity $\left(\mathrm{m} / \mathrm{s}^{2}\right)$.

For most reservoirs, Equation (4) gives: $t<<1$ second, so the inertia effect is not relevant for times larger than a few minutes after the start of depletion. In conclusion, the inertia of the overburden can be ruled out as a cause for the observed subsidence delay effect.

\subsection{Mechanism III: Reservoir Compaction}

There are several reservoir compaction mechanisms that can cause a subsidence-depletion delay effect:

- natural over-compaction;

- creep of the reservoir rock;

- an intrinsic rate effect;

- an elastic-plastic transition.

\subsubsection{Natural Over-Compaction}

Natural over-compaction of a reservoir can be the result of over-pressurisation of the reservoir or a previous deeper burial during its geological history. For stresses below the previous maximum effective stress the reservoir rock deformation is dominated by elasticity while above this previous maximum effective stress, inelastic deformation is triggered. Figure 10 shows the effect of natural overcompaction on reservoir compaction due to production.

Inelastic compaction mechanisms become active when depletion has reduced the reservoir pressure such that the maximum previous effective stress is reached. The overpressure of a reservoir is defined as:

$$
p_{\text {over }}=p_{\text {res }, 0}-\gamma_{p} \cdot(T V D+w d)
$$

Here:

$P_{\text {res, } 0}=$ the initial reservoir pressure $(\mathrm{MPa})$

$\gamma_{p}=$ the hydrostatic pore pressure gradient (set to $0.01 \mathrm{MPa} / \mathrm{m}$ )

$T V D=$ the true vertical depth subsurface or sub seafloor (m)

$w d=$ the seawater depth $(\mathrm{m})$.

The unloading of the rock during its geological history (from point $P$ to $Q$ in Fig. 10) can be caused by (a) an

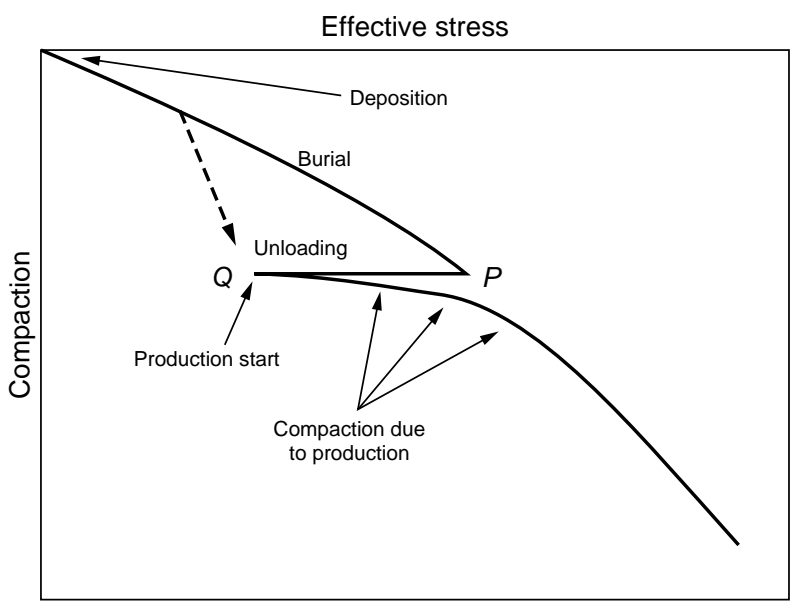

Figure 10

Effective vertical stress versus compaction for a natural overcompacted reservoir (after Merle et al., 1976). Dashed line represents gradual over-pressurisation during natural compaction.

increase in pore fluid pressure or by (b) a decrease in total vertical stress. In case (a), the reservoir has followed path in Figure 11, which gives an over-compaction stress of:

$$
\sigma_{\text {over }}^{\prime}=\sigma_{\max }^{\prime}-\sigma^{\prime}\left(Q_{1}\right)=P_{\text {over }}
$$

Here $\sigma_{\text {max }}^{\prime}$ is the maximum effective stress that the reservoir has seen in the past. In case (b), the reservoir has followed path in Figure 11, which gives an over-compaction stress of:

$$
\sigma_{\text {over }}^{\prime}=\sigma_{\max }^{\prime}-\sigma^{\prime}\left(Q_{2}\right)=\frac{\gamma_{S}}{\gamma_{P}} \cdot P_{\text {over }}
$$

Here $\gamma_{s}$ is the overburden stress gradient (about $0.02 \mathrm{MPa} / \mathrm{m}$ ). In both cases, the maximum over-compaction stress is proportional to the present-day over-pressurisation. This assumes that the reservoir has not been over-pressured gradually to its present stress state during natural compaction. The effect of gradual over-pressurisation is shown in Figure 10 and Figure 11 as a dashed line and may lead to under-compaction.

For the offshore fields Valhall, Ekofisk and Troll, the average seawater depths are respectively 70, 73 and $303 \mathrm{~m}$. Figure 12 shows the reservoir over-pressures versus the subsidence-depletion delay. The results divides the dataset into two groups:

- The shallow reservoirs (with a depth less than about $2 \mathrm{~km}$ ) have a subsidence-depletion delay which is comparable to their over-pressurisation.

- The deep reservoirs (with a depth range of 2450 to $4300 \mathrm{~m}$ ) have a subsidence-delay that is much less than their over-pressurisation. 


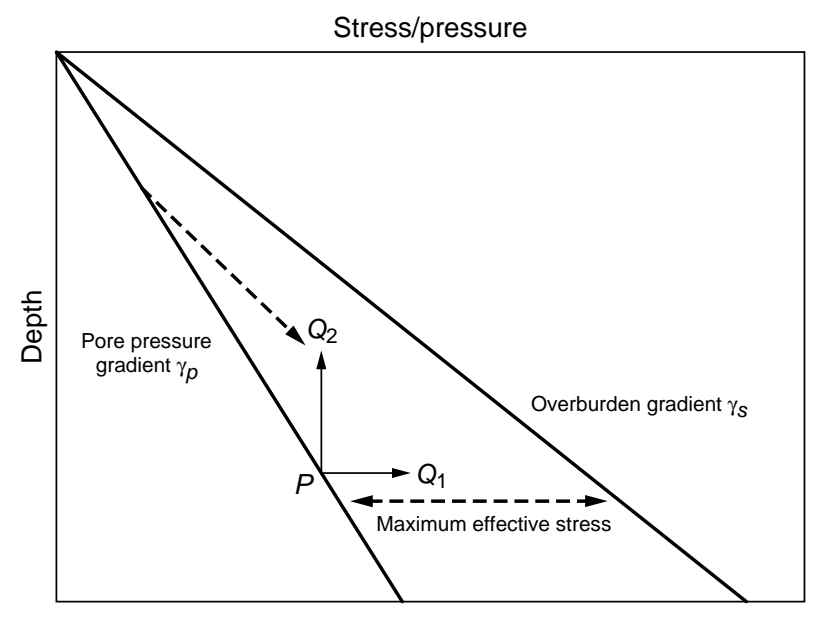

Figure 11

Stress versus depth, showing how the over-compaction stress is related to the overburden gradient and the pore pressure gradient. Dashed line represents gradual over-pressurisation during natural compaction

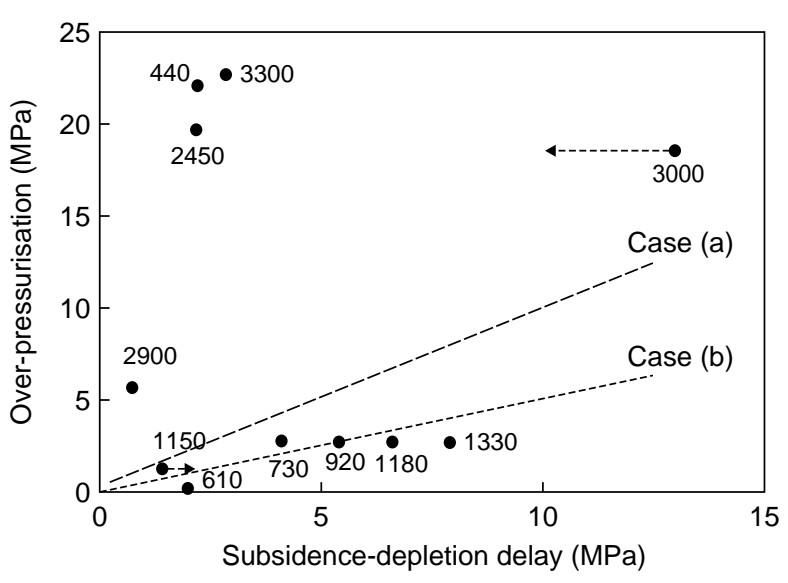

Figure 12

Reservoir overpressures versus the subsidence-depletion delay. The labels are the reservoir depths (in meter). Dashed lines refer to predictions based on two over-compaction mechanisms.

\subsubsection{Creep Behaviour of Rock}

The subsidence delay effect could be caused by creep behaviour of the reservoir rock, as observed in laboratory core experiments. However, during the subsidence delay, the reservoir seems to show a more stiff behaviour than measured on core material, while creep in general will increase the strain, causing the reservoir apparently to behave "less stiff" (Eiksund et al., 1995; Schutjens et al., 1995; Hettema, 1996; Critescu and Hunsche, 1997). Besides, in laboratory experiments on core material, creep deformation usually becomes relevant at higher stresses, close to shear failure or pore collapse. Nevertheless, creep behaviour cannot be ruled out as a subsidence-delay mechanism.

\subsubsection{An Intrinsic Rate Effect of Rocks}

There is a large difference in loading rate between geological loading rates (typically $<10^{-4} \mathrm{MPa}$ /year) and field depletion rates (1-10 MPa/year). It is possible that a "geologically instantaneous" increase in loading rate of several orders of magnitude is accompanied by a time delay effect. De Waal and Smits (1985) have developed a mathematical model to relate the compaction to both the geological and the depletion-induced loading rates. The key to understanding loading rate effects lies in the analysis of the grain scale micro-mechanism, and more specifically, to the relationship between local thermodynamic driving force and kinetics of the grain-scale deformation mechanism(s) like stresscorrosion cracking (Atkinson, 1987) or pressure solution (Lehner, 1995).

\subsubsection{An Elastic-Plastic Transition}

The in situ reservoir rock may behave upon depletion initially elastically with a relatively high stiffness. After the effective stress has increased due to depletion, some plastic compaction limit may have been exceeded to cause compaction to occur at rates observed in the field (after the initial period). This scenario requires that during initial depletion, the in situ reservoir rock behaves stiffer than what is usually measured on core material. It also requires a clear transition from elastic to plastic behaviour at effective stresses relatively close to the initial. For chalk, nonlinear material behaviour has often been observed in laboratory core experiments (Johnson et al., 1989). For clastic reservoir rock, laboratory core experiments seldom show an initial high stiffness or a clear elastic-plastic transition. This could be due to coring-induced damage. During the coring process the in situ stresses are completely released and as a consequence, micro-structural changes can alter the rock's mechanical properties beyond restoration (Holt et al., 1994; Holt et al., 2000).

\subsection{Mechanism IV: Deformation of the Over-, Under- and side-burden}

When a reservoir is depleted, the reaction of the surrounding rock mass to the pore-pressure changes and reservoir compaction can be time-delayed or noninear dependent on pore pressure. Stresses and strains in the surrounding rock changes as the reservoir compacts. There can be an active 
tectonic stress component, the stress path can change and stress arching can occur. To investigate these effects in depth requires full-field geo-mechanical modelling, which is outside the scope of this article. One possible effect of the overburden that could cause a subsidence-depletion delay is depletion-dependent stress arching (Adachi et al., 1997; Papamichos et al., 2001). The geometric effect of the overburden arch is expected to be related to the depth/width ratio of the reservoir. The average depths are given in Table 1 and for the widths the minimum value is used. Figure 13 shows the subsidence-depletion delay versus the reservoir depth/width ratio for the investigated fields. The lack of correlation suggests that the subsidence-delay is not caused by stress-dependent arching of the overburden, but more detailed investigations are required to rule this mechanism out. This does not rule out other overburden-related effects, such as compaction-induced deformation, stress path changes, creep or pore-pressure depletion close to the reservoir-overburden boundary.

\section{DISCUSSION}

The analysed data from eight fields suggest a subsidence versus reservoir depletion relation as depicted schematically in Figure 14. When depletion starts there may be a subsidence delay. The most reliable data for the presence of subsidence delay are those for the Groningen, Ameland and Troll fields. After the subsidence delay period, there is a phase referred to in the Figure 14 as near-linear subsidence, where a linear relation is observed between subsidence and depletion. The subsidence during this period is small, in the order of centimetres, usually does not have operational consequences and it is therefore often overlooked or not measured in the field (e.g. the Ekofisk field in Figure 8 where the first measurement was made after 8 years of production). After the near-linear subsidence phase, the accelerated subsidence phase follows, characterized by a significantly larger subsidence, often in the order of meters. When data are not recorded during the near-linear subsidence period it is often assumed that there is no subsidence, which may be a misinterpretation of the data. This is illustrated in Figure 14 where in the absence of early subsidence measurements, the data during the accelerated subsidence period are extrapolated to zero subsidence resulting in an apparent significant subsidence delay. This is probably the case for the Ekofisk and Venezuelan field data, which give a large subsidencedepletion delay. For these reasons, the amount of reliable field data on the initial part of the subsidence-depletion relation is too limited to draw definite conclusions on the subsidence delay issue.

It can be argued that the subsidence-depletion behaviour of Figure 14 applies to all reservoirs provided that they are sufficiently depleted. Depletion may produce sufficiently large effective stresses in the reservoir to cause extensive reservoir compaction, e.g. due to pore collapse and grain crushing, and/or trigger other non-reversible failure mechanisms, such as arch collapse, activation of existing or creation of new faults, etc. Reservoirs where the transition point has been exceeded are characterized by significant subsidence (e.g. Ekofisk, Valhall, Bolivar Coast). However, in many reservoirs the depletion never exceeds the near-linear to accelerated subsidence transition point and therefore the subsidence remains limited (e.g. Lacq, Groningen, Ameland).

Our analysis suggests that there are two classes of reservoirs:

- Class I of reservoirs in the near-linear subsidence regime. They are usually well cemented, often old (older than of

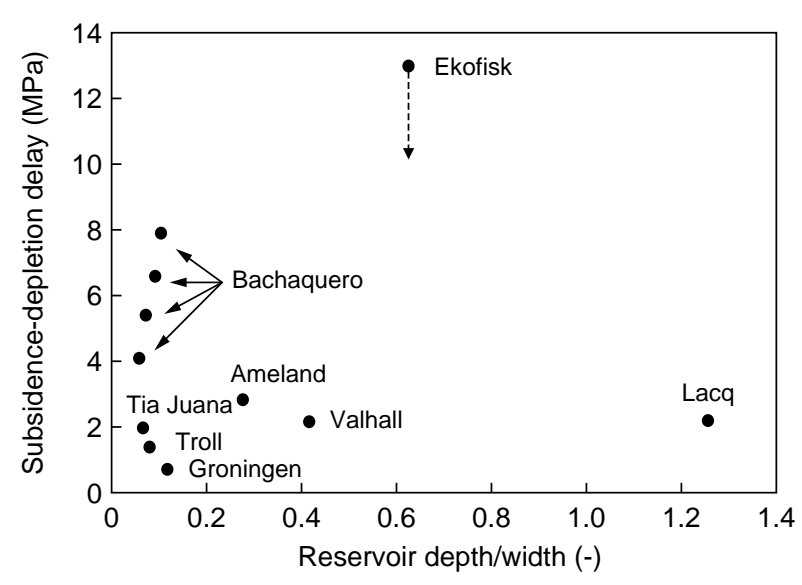

Figure 13

Subsidence-depletion delay versus the reservoir depth/width ratio.

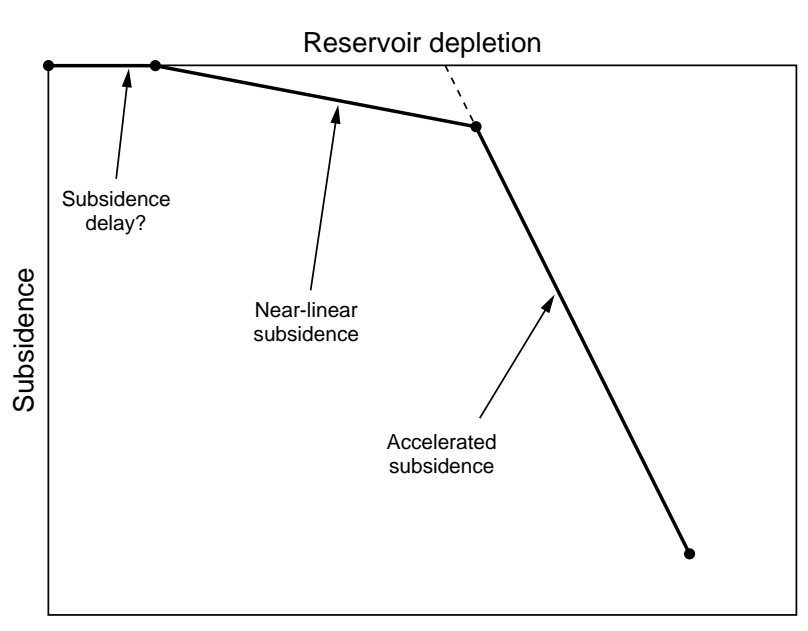

Figure 14

Schematic of subsidence versus reservoir depletion relation. 
Cretaceous age) and at present deep (> $2 \mathrm{~km})$. Subsidence is often small (less than a few decimetres).

- Class II of reservoirs in the accelerated subsidence regime. They are usually un-cemented or poorly cemented granular aggregates like sand, silt, chalk and diatomite, bounded together by small amounts of cement or capillary forces. These are often of high porosity, young (younger than of Cretaceous age) and presently buried at relatively shallow depths (often $<2 \mathrm{~km}$, with the exception of the highly over-pressured chalk reservoirs). Initially, in their near-linear subsidence period, these reservoirs show little compaction and subsidence. Decades of low compaction and subsidence during production have been reported from Venezuelan fields and the Californian diatomite fields. During the accelerated phase, subsidence often becomes very large (a few meters).

Data from the investigated fields do not support conclusive evidence for the operation of one dominant subsidence delay mechanism. Eight fields are simply not enough to be able to separate the effects of important parameters that are widely ranged, such as depth, hydrocarbon type and rock type. It is, however, possible to limit the potential effect of some mechanisms.

For all fields the transient production times appear to be much shorter than their delay times. The Ameland field, the Tia Juana field, the Troll East field and the Valhall field have calculated transient times of about $10 \%$ of their observed delay times. It is concluded that the observed subsidence time delays cannot be caused by pressure diffusion effects alone, although this effect will always contribute to some degree. Calculations of characteristic depletion times over lowpermeability zones (Table 4) have shown that time-delays in the order of years can occur for realistic zone dimensions. However, unless these structures make up a significant part of the reservoir volume, this effect cannot explain a subsidence-depletion delay over the entire reservoir.

There are several reservoir compaction mechanisms that can cause a subsidence-depletion delay effect. Natural overcompaction can result in a subsidence depletion delay due to high initial reservoir stiffness. Figure 12 shows that for the shallow reservoirs, natural over-compaction, e.g. due to a previous deeper burial of the reservoir, has the potential to cause the observed subsidence-depletion delay. The deeper reservoirs are too much over-pressured to explain their subsidence-depletion delay by over-compaction. These deeper reservoirs are geologically older than the shallow reservoirs, so that there is a larger chance that their over-pressurisation has not occurred during a recent geological event. It is also possible that the over-pressurisation occurred gradually during their natural compaction, so that the reservoir is actually under-compacted (see dashed lines in Fig. 10 and Fig. 11). This seems to be the case for the highly porous, overpressured chalk reservoirs. For sandstone reservoirs, on the other hand, Bjørkum and Nadeau (1998) have shown that at temperatures above $120^{\circ} \mathrm{C}$, porosity loss due to quartz cementation is capable of generating fluid overpressure. In that case the assumed simple mechanical relationship between over-pressurisation and over-compaction is not longer valid. Either way, it is unlikely that the older reservoirs have experienced the maximum over-compaction as determined from today's reservoir overpressures (see Fig. 12). This explains why the deeper reservoirs show little subsidencedepletion delay compared to their over-pressurisation.

The over-compaction mechanism and the elastic-plastic mechanism are strongly related to each other. Both lead to a high initial reservoir stiffness and both are intrinsically stress related. The other two reservoir compaction mechanisms (creep behaviour and the rate effects of rocks) are also strongly related to each other, because both are intrinsically time controlled. All four compaction-related mechanisms are difficult to quantify from laboratory measurements, because results are extremely sensitive to possible core damage. Effects of natural over-compaction and the elastic-plastic transition can easily be erased by core damage (Holt et al., 2000). On the other hand, for the determination of creep behaviour and an intrinsic rate effect, coring-induced alteration tends to overshadow the in situ reservoir behaviour. Micro-cracks possibly generated during coring are a source for inelastic time-dependent deformation mechanisms (Schutjens et al., 1995; Hettema, 1996).

\section{CONCLUSIONS}

Subsidence data of all eight fields support the existence of a subsidence-depletion delay effect. Subsidence-depletion delay pressures range from 0.7 to $10 \mathrm{MPa}$. The time-delays corresponding to the subsidence-depletion delays are in the range of 1.6 to 13 years.

The data suggests two classes of reservoirs:

- Class I of reservoirs are usually well cemented, old (older than of Cretaceous age) and at present deep (> $2 \mathrm{~km})$. Their compaction and subsidence are usually small (less than a few decimetres).

- Class II of reservoirs are usually un-cemented or poorly cemented granular aggregates like sand, silt, chalk and diatomite. These are often of high porosity, young (younger than of Cretaceous age) and buried at relatively shallow depths (often $<2 \mathrm{~km}$ ). After an initial near-linear period, compaction and subsidence enters the accelerated regime, leading to a large subsidence (a few meters).

For all fields the transient production times were found to be much shorter than their delay times. However, the mechanism of pore pressure diffusion always contributes to the subsidence delay effect. This is especially important for highly viscous oil reservoirs or for reservoirs produced with a relatively large average drainage area per production well. 
Based on a theoretical model, time-delay effects due to the inertia of the overburden could be ruled out as a mechanism for the subsidence delay effect.

For the shallow reservoirs, natural over-compaction has the potential to cause the observed subsidence-depletion delays. The deeper reservoirs are more than enough overpressured to explain their subsidence-depletion delay, but due to their long burial history they have probably not experienced the maximum over-compaction as determined from today's reservoir overpressures, because:

- they could have been over-pressured gradually during natural compaction.

- at higher temperatures (above about $120^{\circ} \mathrm{C}$ ), other mechanisms of over-pressurisation and compaction may become active in sandstone.

The reservoir compaction-related delay mechanisms are difficult to quantify from laboratory measurements, because the results are extremely sensitive to possible core damage.

There is no correlation between the subsidence delay values and the depth/width ratio of the reservoirs, but more investigations are needed to rule out stress changes and arching of the overburden as a cause for the subsidencedepletion delay.

\section{ACKNOWLEDGEMENTS}

The management of SINTEF Petroleum Research (Trondheim, Norway) and Shell Exploration and Production Research (SIEP-RTS, Rijswijk, The Netherlands) supported a researcher exchange program which allowed Peter Schutjens to work for one year at SINTEF Petroleum Research. This work was done during this period. The authors also wish to thank The Dutch Oil Company (NAM) for providing subsidence and pressure data and for giving their permission to publish it. We also thank Eiliv Skomedal of STATOIL for his critical review of the document.

\section{REFERENCES}

Adachi, T., Kimura, M., Nishimura, T., Koya, N. and Kosaka, K. (1997) Trap Door Experiments under Centrifugal Conditions. Proc. Deformation and Progressive Failure in Geomechanics. Nagoya Asoaka et al. (eds.) Pergamon-Elsevier Science, 725730.

Atkinson, B.K. (ed.) (1987) Fracture Mechanics of Rock, Academic Press, London.

Best, M.E. and Katsube, T.J. (1995) Shale Permeability and its Significance in Hydrocarbon Exploration. The Leading Edge, March, 165-170.

Bjørkum, P.A. and Nadeau, P.H. (1998) Temperature Controlled Porosity/Permeability Reduction, Fluid Migration and Petroleum Exploration in Sedimentary Basins. APPEA Journal, 38, Part 1, 453-464.

Borchers, J.W. (ed.) (1998) Land Subsidence Case Studies and Current Research. Association of Engineering Geologist, Special
Publication No. 8. Proc. the Dr. Joseph F. Poland Symp. on Land Subsidence, Star Publishing.

Boutéca, M.J., Fourmaintreaux, D. and Meimon, Y. (1990) In situ Measurement And Numerical Modelling of the Reservoir Compaction and of the Induced Surface Subsidence. Proc. European Oil and Gas Conf., Altavilla Milicia, Palermo, Italy, G. Imarisio et al. (eds.), Graham and Trotman, 260-271.

Boutéca, M.J., Sarda, J.P. and Schneider, F. (1996) Subsidence Induced by the Production of Fluids. Revue de l'Institut français du pétrole, 51, 3, 365-379.

Cook, C.C. and Jewell, S. (1996) Simulation of a North Sea Field Experiencing Significant Compaction Drive. SPE Reservoir Evaluation and Engineering, 48-53.

Cook, J. (1999) The Effects of Pore Pressure on the Mechanical and Physical Properties of Shales. Oil and Gas Science and Technology, Rev. de l'IFP, Éditions Technip, 54, 6, 695-701.

Critescu, N.D. and Hunsche, U. (1997) Time Effects in Rock Mechanics, John Wiley and Sons, New York.

Doornhof, D. (1992). Surface Subsidence in The Netherlands: The Groningen Gas Field. Geologie en Mijnbouw, 71, Kluwer Academic Publishers, 119-130.

Eiksund, G., Svanø, G. and Nagel, N.B. (1995). Creep related subsidence caused by oil and gas extraction. Proc. $5^{\text {th }}$ Intl. Symp. on Land Subsidence, The Hague, The Netherlands. Barends, F.B.J., Brouwer, F.J.J. and Schröder, F.H. (eds), IAHS Publication. no. 234. 277-285.

Finol, A.S. and Sancevic, Z.A. (1995) Subsidence in Venezuela. In Subsidence Due to Fluid Withdrawl. Developments in Petroleum Science, Chilingarian G.V., Donaldson E.C., and Yen T.F. (eds.), Elsevier Science, Amsterdam, 41, 337-372.

Fjær, E., Holt, R.M., Horsrud, P., Raaen, A.M. and Risnes, R. (1992) Petroleum Related Rock Mechanics. Developments in Petroleum Science, Elsevier Science, Amsterdam.

Freeze, R.A. (2000) Social Decision Making and Land Subsidence. Proc. $6^{\text {th }}$ Intl. Symp. on Land Subsidence. In Land Subsidence, Carbognin L., Gambolati G.and Johnson A.I. (eds.), Ravenna, Italy, 353.

Geertsma, J. (1973) A Basic History of Subsidence Due to Reservoir Compaction: The Homogeneous Case. Verh. Kon. Ned. Geol. Mijnbouwk. Gen., 28. 43-62.

Geertsma, J. and Van Opstal, G. (1973) A Numerical Technique for Predicting Subsidence Above Compacting Reservoirs, Based on the Nucleus of Strain Concept. Verh. Kon. Ned. Geol. Mijnbouwk. Gen., 28, 63-78.

Golan, M. and Whitson, C.H. (1996) Well Performance, $2^{\text {nd }}$ edition, Tapir, Norway.

Hettema, M.H.H. (1996) The Thermo-Mechanical Behaviour of Sedimentary Rock: An Experimental Study. PhD Thesis, Delft University of Technology, ISBN 90-5651-021-5, Eburon P \& L, Delft, The Netherlands.

Hettema, M.H.H., Schutjens, P.M.T.M., Verboom, B.J.M. and Gussinklo, J. (2000) Production-Induced Compaction of a Sandstone Reservoir: The Strong Influence of Stress Path. SPE 65410, Reservoir Eval. \& Eng. 3, 4, 342-347.

Holt, R.M., Brignoli, M., Fjær, E., Unander, T.E. and Kenter, C.J. (1994) Core Damage Effects on Compaction Behaviour. Proc. SPE/ISRM Rock Mechanics in Petroleum Engineering, SPE 28027, Delft, The Netherlands, Balkema, Rotterdam, 55-62.

Holt, R.M., Brignoli and M., Kenter, C.J. (2000) Core Quality: Quantification of Coring-Induced Rock Alteration. Int. J. Rock Mech. Min. Sci., 37, 6, 889-908.

Horsrud, P. Sønstebø, E.F. and Bøe, R. (1998) Mechanical and Petrophysical Properties of North Sea shales. Int. J. Rock Mech. Min. Sci., 35, 8, 1009-1020. 
Johnson, J.P., Rhett, D.W. and Siemers, W.T. (1989) Rock Mechanics of the Ekofisk Reservoir in the Evaluation of Subsidence. J.P.T. July., SPE 17854, 717-722.

Jones, M. and Mathiesen, E. (1993) Pore Pressure Change and Compaction in North Sea Chalk Hydrocarbon Reservoirs. Int. J. Rock Mech. Min. Sci. \& Geom. Abstr,. 30, 1205-1208.

Layrisse, I. (1999) Heavy Oil Production in Venezuela: Historical Recap and Scenarios for Next Century. SPE Int. Symposium on Oilfield Chemistry, 53464, Houston, 749-761.

Lehner, F.K. (1995) A Model for Intergranular Pressure Solution in Open Systems. In Influence of Fluids on Deformation Processes in Rocks, Spiers C.J. and Takeshita (eds), Tectonophysics, 245, 153-170.

Mathiesen, E. (1996) Rock Mechanics and Chalk: Does Future Modeling of Rock Mechanical Related Phenomena in Chalk Require the Development of Fully Coupled Models? Proc. $5^{\text {th }}$ North Sea Chalk Symposium, Reims, France.

McLendon, T.H. (1991) Performance Prediction for the M-6 Area of the Tia Juana Field Using a Rate-Dependent Pore Volume Compressibility Model and Extended Material Balance. SPE Ann. Tech. Conf. \& Exhib., 22939., Dallas, USA, 553-564.

Merle, H.A., Kentie, C.J.P., van Opstal, G.H.C.and Schneider G.M.G. (1976) The Bachaquero Study - A Composite Analysis of the Behavior of a Compaction Drive/Solution Gas Drive Reservoir. SPE JPT, September, 1107-1115.

Mobach, E. and Gussinklo, H.J., 1994. In situ Reservoir Compaction Monitoring in the Groningen Field. Proc. SPE/ISRM Rock Mechanics in Petroleum Engineerin, Delft, The Netherlands. Balkema, Rotterdam, 535-547.

Nagel, N.B. (1998) Ekofisk Field Overburden Modelling. Proc. Eurock Rock Mechanics in Petroleum Engineering, SPE/ISRM 47345, 2, Trondheim, Norway ,177-186.

Núñez, O. and Escojido, D. (1976) Subsidence in the Bolivar Coast. Int. Assoc. Hydrol. Sci. Proc. Annaheim Symp., Publication 121, 257-266.

Opstal, G.H.C. van (1974) The Effect of Base-Rock Rigidity on Subsidence Due to Reservoir Compaction. Proc. $3^{\text {rd }}$ Congr. of the Int. Soc. of Rock Mech., Denver, II, Part B, 1102-1111.

Papamichos, E., Vardoulakis and I., Heill, L.K. (2001) Overburden Modelling Above a Compacting Reservoir Using a Trap Door Apparatus. Phys. Chem. Earth (A), 26, 1-2, 69-74.
Pattillo, P.D., Kristiansen, T.G., Sund, G.V. and Kjelstadli, R.M. (1998) Reservoir Compaction and Seafloor Subsidence at Valhall. Proc. Eurock Rock Mechanics in Petroleum Engineering, SPE/ISRM 47274,Trondheim, Norway, 1, 377-386.

Rolando, J.P., Massonnat, G.J., Grasso, J.R., Odonne, F.and Meftahi, R. (1997) Characterization and Modelling of Increasing Permeability While Producing a Gas Fractured Reservoir. SPE Ann. Tech. Conf. \& Exhib., 38711, San Antonio, Texas, 579-589.

Schutjens, P.M.T.M., Fens, T.W. and Smits, R.M.M. (1995) Experimental Observations of the Uniaxial Compaction of Quartz-Rich Reservoir Rock at Stresses up to $80 \mathrm{MPa}$. Proc. $5^{\text {th }}$ Int. Symp. on Land Subsidence, The Hague, Netherlands. In Land subsidence, Barends, Brouwer and Schröder (eds.), Balkema, Rotterdam, 389-408.

Schutjens, P.M.T.M., van Dijk, C., Marcelis, F., Pruno, S., Martin, J.W. and van den Oord, R. (2000) Compaction of a poorly consolidated quartz-rich reservoir sandstone. Experiments for the analysis of compaction drive. Proc. $6^{\text {th }}$ Int. Symp. on Land Subsidence, Ravenna, Italy. In: Carbognin, L., G. Gambolati and A. I. Johnson (eds.), Land Subsidence. 191-213.

Schutjens, P.M.T.M., Hanssen, T.H., Hettema, M.H.H., Merour, J., de Bree, J.Ph., Coremans, J.W.A. and Helliesen, G. (2001) Compaction-induced porosity/permeability reduction in sandstone reservoirs: Data and models for the elasticitydominated deformation. SPE Ann. Techn. Conf. \& Exhib. New Orleans. SPE 71337.

Sneed, M., Pavelko, M.T. and. Galloway, D.L. (2000). Modeling Residual Aquifer-System Compaction: Constraining the Vertical Hydraulic Diffusivity of Thick Aquifers. Proc. $6^{\text {th }}$ Intl. Symp. on Land Subsidence, Ravenna, Italy. In Land Subsidence, Carbognin L., Gambolati G. and Johnson A.I. (eds.), 343-355.

Terzaghi, K. (1950). Report on the Effects Of The Terminal Island Subsidence on Long Beach Steam Station of The Southern California Edison Compan, Consulting Report, Winchester (on File in The Terzaghi Library of The Norwegian Geotechnical Institute, Oslo)

Waal, J.A. de and Smits, R.M.M. (1985). Prediction of Reservoir Compaction and Surface Subsidence: Field Application of a New Model. SPE Ann. Tech. Conf. \& Exhib., 14214, Las Vegas

Final manuscript received in June 2002 


\section{APPENDIX A: \\ DYNAMIC EFFECT DUE TO THE INERTIA OF THE OVERBURDEN}

In this Appendix, the time-dependent effects due to the inertia of the overburden are determined. The model describes the dynamic effect of the overburden on the reservoir compaction in response to pressure depletion at a constant rate. The most important model assumptions are:

- The model is $1 \mathrm{D}$, so only the overburden directly overlying the reservoir is considered (which is assumed to be completely uncoupled to the rest of the Earth).

- The overburden is regarded as a point mass.

- The underburden is fixed.

- Linear poroelastic reservoir behaviour.

According to Newton's second law, the forces are related to mass and acceleration by:

$$
\sum F=M \cdot \ddot{z}
$$

Here:

$F$ is the force $(\mathrm{N})$

$M$ is the mass of the overburden $(\mathrm{kg})$

$z$ is the displacement ( $\mathrm{m})$.

The double dots represent the second derivative with respect to time. For this problem the vertical displacement $z$ is taken at the plane between the overburden and reservoir (downward is positive). The mass of the overburden can be written as:

$$
M=\int \rho d V=A \cdot \bar{\rho} \cdot z_{r e s}=A \cdot \frac{\sigma_{r e s, 0}}{g}
$$

Here:

$\rho \quad$ is the bulk density of the overburden rock $\left(\mathrm{kg} / \mathrm{m}^{3}\right)$

$V \quad$ is the volume of the overburden $\left(\mathrm{m}^{3}\right)$

$A \quad$ is the surface area of the top of the reservoir $\left(\mathrm{m}^{2}\right)$

$\bar{\rho} \quad$ is the average bulk density of the overburden $\left(\mathrm{kg} / \mathrm{m}^{3}\right)$

$z_{\text {res }} \quad$ is the thickness of the overburden (m)

$\sigma_{\text {res, } 0}$ is the initial total vertical stress at the top of the reservoir $(\mathrm{Pa})$

$g \quad$ is the acceleration of gravity $\left(\mathrm{m} / \mathrm{s}^{2}\right)$.

Note that the total vertical stress is assumed to be solely the result of the weight of the overburden. The forces acting in vertical direction on a plane at the top of the reservoir are:

$$
\sum F=F_{\text {down }}-F_{\text {up }}=M g-A\left[\sigma_{\text {res }, 0}+\Delta \sigma_{r e s}^{\prime}+\beta \Delta p\right]
$$

Here:

$\Delta \sigma_{\text {res }}^{\prime}$ is the change in effective vertical stress in the reservoir rock $(\mathrm{Pa})$

$\beta \quad$ is Biot's effective stress parameter (-)

$\Delta p \quad$ is the pore pressure change (negative for depletion) $(\mathrm{Pa})$.
Initially the system is at rest and the sum of the forces equals zero, because the overburden weight is balanced by the reservoir rock frame stress and pore pressure. Due to depletion, the reservoir pore pressure decreases and the rock stress changes according to the theory of elasticity. Combining Equations (A2) and (A3) gives for the forces:

$$
\sum F=-A \cdot\left[\varepsilon_{z} K_{u}+\beta \Delta p\right]
$$

Here

$\varepsilon_{z}$ is the vertical strain in the reservoir (-)

$K_{u}$ is the confined modulus $(\mathrm{Pa})$.

The reservoir is depleted with a constant rate: $\Delta p=-R \cdot t$. The vertical reservoir strain can be written as: $\varepsilon_{z}=z / T_{\text {res }}$. Combining Equations (A4) and (A2) with (A1) and rearranging gives:

$$
\ddot{z}+\left(\frac{K_{u} g}{T_{\text {res }} \sigma_{\text {res }, 0}}\right) \cdot z=\frac{g \beta R}{\sigma_{\text {res }, 0}} \cdot t
$$

Here:

$T_{\text {res }}$ is the thickness of the reservoir (m)

$R$ is the pressure depletion rate $(\mathrm{Pa} / \mathrm{s})$.

In this model, the compacting reservoir/overburden system is mechanical analogue to a forced oscillation of a body on a spring, loaded with a force increasing linear with time. It is an inhomogeneous harmonic oscillator without damping. The solution of the homogeneous part of the differential equation (setting the right hand side of Equation $(\mathrm{A} 5)=0)$ is:

$$
z(t)=p \cos (\omega t)+q \sin (\omega t)
$$

where $p$ and $q$ are integration constants and the circular frequency is:

$$
\omega=\sqrt{\frac{K_{u} g}{T_{r e s} \sigma_{r e s, 0}}}
$$

The general solution of Equation (A5) is written as:

$z(t)=p \cos (\omega t)+q \sin (\omega t)+\frac{g \beta R}{\sigma_{r e s, 0} \omega^{3}} \cdot(\omega t-\sin (\omega t))$

The Earth is assumed initially (at $t=0$ ) at rest. The initial conditions are:

$$
\begin{aligned}
& z(0)=0 \\
& \dot{z}(0)=0
\end{aligned}
$$

The initial conditions give: $p=0$ and $q=0$. The solution (A8) can be written as:

$$
z(t)=\frac{\beta T_{r e s}}{K_{u}} \cdot R \cdot t \cdot\left(1-\frac{\sin (\omega t)}{\omega t}\right)
$$




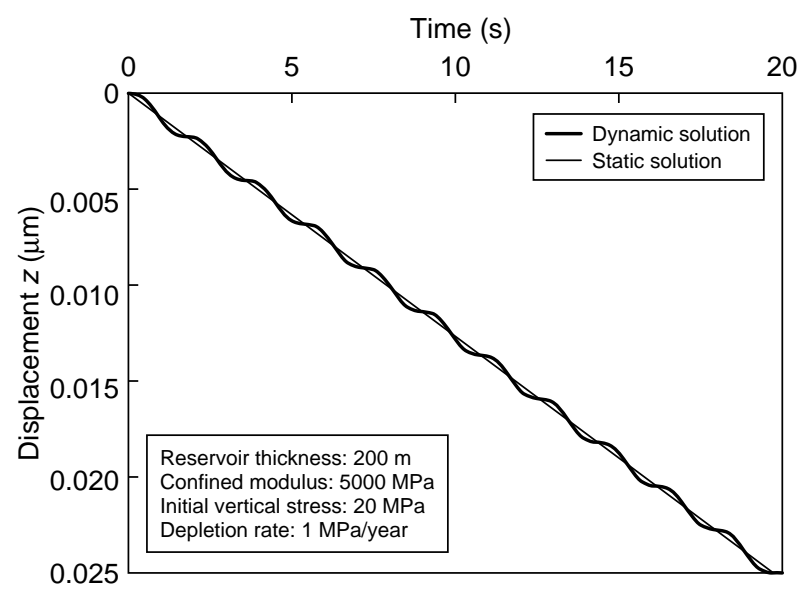

Figure A1

Displacement of a point at the top of the reservoir during depletion at constant rate, for the dynamic and the static solution.
Note that this solution keeps on oscillating over time, because the system is not damped. In reality, the oscillations will be slightly damped due to the internal friction of the reservoir rock. If we do not consider dynamic effects, the forces are balanced during compaction. From Equation (A4) it follows directly that the static solution is:

$$
z(t)=\frac{\beta T_{r e s}}{K_{u}} \cdot R \cdot t
$$

Figure A1 shows these solutions graphically. The input parameters are shown in the figure, giving (from Eq. A7): $\omega=3.5 \mathrm{rad} / \mathrm{s}$. Comparison of the dynamic solution (A10) with the static solution (A11) shows that inertia effects of the overburden are not relevant if $\omega t>1$, or if:

$$
t>>\frac{1}{\omega}=\sqrt{\frac{T_{r e s} \sigma_{r e s, 0}}{K_{u} g}}
$$

